\title{
Analysis of adolescent satisfaction with the quality of their physical education classes
}

\author{
KATERINA KRALOVA* [0 and LUDMILA FIALOVA
}

Department of Pedagogy, Psychology and Didactics of PE and Sport, Faculty of Physical Education and Sport, Charles University in Prague, Prague, Czech Republic

\section{RESEARCH PAPER}

Received: August 30, 2020 • Accepted: December 2, 2020

Published online: April 10, 2021

(C) 2021 The Author(s)

\begin{abstract}
Objective: A lack of movement in adolescence is a pressing issue for modern society. Physical education at school can have a major influence on the movement habits of adolescents, since it can offer curriculum that gives students ideas for leisure time while entertaining them and also respecting physical fitness goals. The aim of this work is to analyze student satisfaction with physical education classes at secondary vocational schools. Methods: Categories were created based on week-long monitoring of walking. Based on the number of steps, students were divided into four categories: active girls/boys and hypoactive girls/boys. In another part of the study, the students filled out the questionnaire created by Antala et al. (2012). Responses to questions regarding questions about unpopular activities, dread of specific activities, and more frequent inclusion of specific activities in PE classes. A $\chi^{2}$ independence test was used to compare data between individual student categories in the combination table. Results: The health recommendations for minimum daily number of steps are met by $65.4 \%$ of boys and $75.8 \%$ of girls aged $15-16$ years. Chi-squared test showed the greatest difference in satisfaction with physical education $(P$-value $<0.001)$ between the hypoactive groups of students. Hypoactive boys are significantly more satisfied with the activities in PE class than hypoactive girls. Dread is more often present among girls than boys and is particularly associated with gymnastics. Activities that students wanted to do more often included ball games (football for boys, volleyball for girls), strength training (listed by $32 \%$ of hypoactive boys) and exercise to music (listed by $49 \%$ of hypoactive girls). Conclusions: We believe that the proper choice of PE activities can increase the popularity of the class, and thus influence the exercise habits of adolescents, including those who are found to have insufficient physical activity.
\end{abstract}

\footnotetext{
*Corresponding author. E-mail: kralo.katerina@gmail.com
} 


\section{KEYWORDS}

physical education, adolescence, satisfaction, step counting, inactivity

\section{INTRODUCTION}

Modern technology has fundamentally contributed to a restriction of daily movement such as walking, which has been replaced by the abundant use of various means of transportation, physical exertion at work has been replaced by sedentary work and housework has been made simpler by numerous home appliances (Church et al., 2011). On the other hand, there has been an increase in the amount of free time, which is rarely filled actively. Watching television, computer games and surfing the Internet have become the most popular leisure activities. These are all passive, sedentary activities to be consumed, contributing to the rise and mass prevalence of "lifestyle diseases" (Alkhatib, 2016; Brettschneider \& Naul, 2007; Powell, 2020).

Physical activity accounts for $20-40 \%$ of total energy expenditure, which helps regulate weight, reduce the amount of stored fat, and increase muscle mass. A lack of physical activity leads to problems with the musculoskeletal system, metabolic disorders (diabetes), hormonal disorders (insulin sensitivity and others), cardiovascular diseases and others (Chang, 2015; Cruiz, 2017; Powell, 2020). This lack of movement affects the entire population, including children and adolescents. Adolescence is a time of life marked by complex personality transformation, and this is evident psychologically, physically and socially. In the initial phase it is associated with biological factors, while the end of this developmental period is associated more with social and psychological factors. It is most commonly presented as the time between 11 and 21 years of age (Arnett, 2019; Smith, 2016).

Childhood and adolescence are considered by numerous authors (Harris \& Cale, 2018; Logstrup, 2001; Meyer \& Gullotta, 2012; Smith, 2016) to be the optimal time for instilling a positive relationship towards sports and physical activities. Bélanger et al. (2015), Diehl \& Higler (2015) and Telama et al. (2014) go on to say that physical activity performed in childhood and adolescence is crucial for acquiring and maintaining a positive lifelong relationship to sports and physical activities. The benefits of physical activity for adolescents can be seen on two basic levels: immediate short-term benefits and transferred benefits, i.e. the possible transfer of health benefits acquired at an early age to adulthood (Meyer \& Gullotta, 2012). According to Powell (2020), this fact contributes to the increasing focus of experts on child and adolescent populations and also places an important task in the hands of schools: to provide opportunities for quality physical activity and to also educate youth in physical education, sports and healthpromoting activities. One of the key goals of the school environment is to influence students in a way that they can establish a positive relationship to physical activities and health-promoting activities that carry over to adulthood and old age. Powell (2020) also talks about the need to establish the habit of voluntary, regular and lifelong physical activity, which is just as important for individuals as, for example, basic hygiene habits.

Physical activities and sport are connected with an interest in fashionable looks and a sense of music and rhythm for girls. Rather than strength and performance, they are impressed by beauty and elegance. The requirement is not only to improve physical appearance but also to increase fitness as a condition for strengthening one's self-confidence and independence. For boys, physical activities that build a masculine appearance are attractive. Bodybuilding and other 
forms of strengthening are popular. However, even during adolescence, boys are still highly motivated by the activity of doing sport (James et al., 2018). Practically speaking, however, the amount of physical activity declines throughout the course of one's life. The first significant reduction is observed when a child enters elementary school. Children are taken from the playful environment of pre-school and seated in classroom chairs; even extracurricular activities are often passive in character (Dishman, Heath, \& Lee, 2018; Powell, 2020). According to Coll, Knuth, Bastos, Hallal, and Bertoldi (2014), another risk period is adolescence, especially after 14 years of age. During adolescence there is a decline in the popularity of physical activities, as well as the frequent abandonment of active sports and sports careers. In earlier developmental periods, the need for movement and adventure is satisfied through physical games. Adolescents, however, are rarely drawn to such activities and themselves tend to seek out virtual and digital experiences, accompanied by minimal physical activity. This is also reflected in the incidence of excess weight and obesity, which according to Sigmundova et al. (2017) afflicts $10 \%$ of the adolescent population in the Czech Republic. The authors further state that only $55 \%$ of boys and roughly $75 \%$ of girls aged $15-18$ meet health recommendations for daily walking. The recommendation cited by the authors $(9,000$ steps per day for girls and 11,000 steps per day for boys) are the bare minimum to adequately exercise the body and maintain physical fitness for the given age categories and gender. Jansa (2017) determined in his research that $40 \%$ of Czech boys aged 15-18 do not engage in any physical activity during their free time. Among girls the figure was 55\%. This and other research (Gába, Rubín, Badura, \& Roubalová, 2018; Sigmundová et al., 2017) shows that the amount of physical activity in Czech adolescents is insufficient with respect to normal and deliberate physical activity.

Knowledge of the habitual behavior of adolescents with respect to physical activity and the ways in which they spend their free time is an important factor for understanding the lifestyle of this group. An important role is played by their relationship to physical education at school. High school physical education is the culmination of compulsory physical education aimed at supplementing, enhancing and verifying motor skills, habits and attitudes.

Classes are mandatory for all students with the exception of short-term and long-term exemptions from a doctor (excusing students from all PE classes or specific activities). High school curriculum requires at least $2 \mathrm{~h}$ of physical education per week. For secondary vocational schools however, this means $2 \mathrm{~h}$ of physical education once every two weeks, since instruction is divided into a week of practical instruction, where students learn a trade, and a week of theoretical instruction, which also includes physical education.

The attitudes of students towards physical education in the Czech Republic and Slovakia were examined in detail by Antala et al. (2012). Their monograph examines the opinions of secondary school students on school physical education, the popularity and demands of these programs, and their ability to motivate students. Research has shown that the popularity of physical education, along with motivation, declines with age. Physical education is significantly less important for girls than boys, and girls are more prone to mention their displeasure with class activities than boys. Generally unpopular activities include gymnastics and athletic fitness exercises. On the other hand, high schoolers would like to have more swimming and competitive sports in their PE classes. Listening to the opinions and attitudes regarding school physical education is important for bringing activities in line with the lifestyle of youth and establishing a positive relationship to physical activity. The purpose of this study is to analyze student satisfaction with physical education classes at secondary vocational schools and analyze what are the difference in satisfaction with $\mathrm{PE}$ between active and inactive adolescents and between boys and girls. 


\section{METHODS}

Research was carried out at vocational schools in the Moravian-Silesian Region and in Prague from the period of October-November 2017. Included in the study were 339 adolescents age 15 and 16 studying at vocational schools who consented to participate in the study along with their parents or legal guardians. Complete responses were collected from 315 of them. Research was based on quantitative methods. Sigma ACTIVO activity trackers and the questionnaire created by Antala et al. (2012) were used to analyze the opinions of adolescents on school physical fitness. The physical activity of respondents (specifically the number of steps per day) was monitored for a period of seven days. After this time, the date from the activity trackers was uploaded to a mobile telephone via Bluetooth by the researcher and then evaluated by the SIGMA ACTIV application. Data were processed only from students with complete results, i.e. from those who wore the bracelet 7 days a week for at least 12 hours a day. This information could be verified in the researcher's mobile application. Information about the number of steps made it possible to divide the students into those who met the recommended minimum number of steps per day (active students) and those who did not meet these recommendations (hypoactive students). In another part of the study, the students filled out the questionnaire created by Antala et al. (2012). From a total of 30 questions, the current study presents data from 4 questions - one closed, two semi-open and one open. These questions addressed the content of physical education classes, specifically the following areas:

-Satisfaction with the offer of sport activities during PE class

-Least favorite activity during PE class

-Dread of specific activities

-Desire to more frequently include a specific activity in PE class

Responses to questions regarding questions about unpopular activities, dread of specific activities, and more frequent inclusion of specific activities in PE classes were placed into categories depending on their content. Less frequent responses which did not fall into any category were placed in the category of "Other".

Due to multiple responses, the sum of percentages in Tables 3-5 exceeds $100 \%$ across each category. A $\chi^{2}$ independence test was used to compare data between individual student categories in the combination table.

\section{RESULTS}

Out of a total of 315 students, $70.5 \%$ met the recommended number of minimum steps per day. As shown in Table 1, these were more often girls (75.8\%). Based on the number of steps it was

Table 1. Fulfillment of movement criteria

\begin{tabular}{lccc}
\hline & Boys & Girls & Total \\
\hline Active & 106 (i.e. $65.4 \%)$ & 116 (i.e. $75.8 \%)$ & 222 \\
Hypoactive & $56($ i.e. $36.6 \%)$ & 37 (i.e. $24.2 \%)$ & 93 \\
Total & 162 & 153 & 315 \\
\hline
\end{tabular}


possible to divide the students into four categories: active boys, active girls, hypoactive boys and hypoactive girls.

A scale from 1 to 5 was used to assess satisfaction with sport activities offered during PE class ranging from (1) very satisfied to (5) very dissatisfied. As shown in Table 2, boys were more satisfied with the activities in PE class than girls. The least satisfied category was hypoactive girls.

Satisfaction with PE activities depends more on a student's gender than his or her level of physical activity. As can be seen in Graph 1, a chi-squared test showed the greatest difference in satisfaction with physical education $(P$-value $<0.001)$ between the hypoactive groups of students. Hypoactive boys are significantly more satisfied with the activities in PE class than hypoactive girls. A difference was also demonstrated when comparing active students and comparing girls

Table 2. Average satisfaction of monitored groups

\begin{tabular}{lcccccc}
\hline & Average & $1(\%)$ & $2(\%)$ & $3(\%)$ & $4(\%)$ & $5(\%)$ \\
\hline Active boys & 2.19 & 17.0 & 53.8 & 22.6 & 6.6 & 0.0 \\
Hypoactive boys & 2.20 & 25.0 & 42.9 & 21.4 & 8.9 & 1.8 \\
Active girls & 2.47 & 7.8 & 46.6 & 37.9 & 6.0 & 1.7 \\
Hypoactive girls & 2.86 & 2.7 & 21.6 & 64.9 & 8.1 & 2.7 \\
\hline
\end{tabular}

(1 - very satisfied; 2 - satisfied; 3 - somewhat satisfied, somewhat dissatisfied; 4 - dissatisfied; 5 - very dissatisfied)

Boys

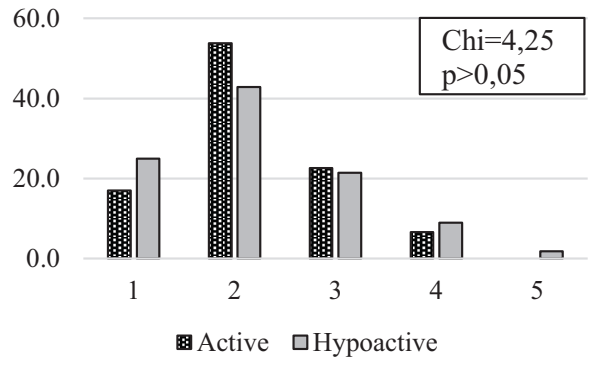

Active

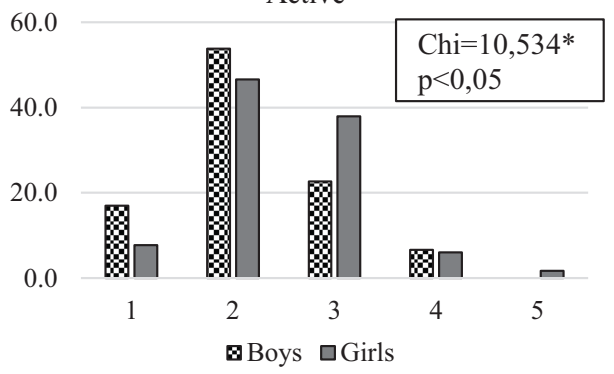

Girls

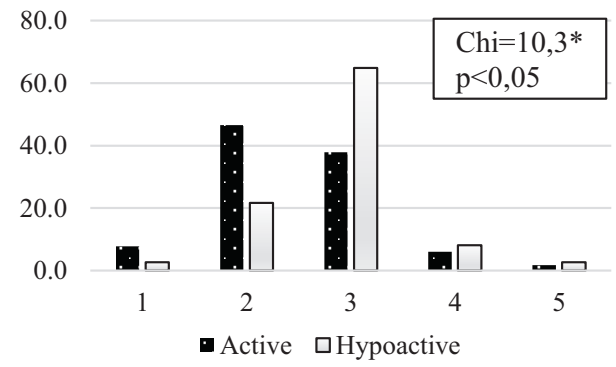

Hypoactive

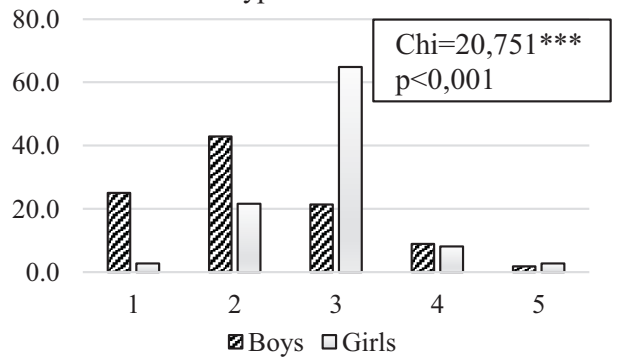

Graph 1. Difference in satisfaction with PE activities (\% of positive responses)

(On a scale of $1-5$, where 1 is very satisfied and 5 is very dissatisfied) 
( $P$-value $<0.05)$. It can thus be said that active boys are more satisfied with $\mathrm{PE}$ activities than active girls and active girls are more satisfied with PE activities than hypoactive girls.

Another question addressed by the questionnaire was whether there were any particular activities in PE class that the students disliked, and what these were. Out of a total of 315 students, 295 gave specific responses. The remaining 20 did not give any response. The 295 students mentioned gave a total of 526 responses, which are listed in categories in Table 3.

All categories of students most frequently listed gymnastic disciplines as their least popular activity in PE class, the boys most often mentioned climbing and exercises on the horizontal bar, the girls also mentioned climbing, exercises on the horizontal bar, and vaulting. A significant difference between categories is seen for athletics, which were disliked by $73 \%$ of hypoactive students, a number significantly higher compared to the other student categories. This primarily concerned long distance running, which was listed by 10 girls (27.0\%). Certain ball games were also relatively unpopular and most frequently mentioned by active students (most often active girls - 51.7\%). Boys most frequently listed football, girls listed basketball and dodgeball.

Differences in unpopular activities between groups of students and gender are shown in Graph 2. Significant differences can be seen when comparing students by activity and gender. The greatest difference is between hypoactive students, with a $P$-level $<0.001$. It can be said that the unpopular activities of hypoactive students depend on their gender. When comparing girls, the difference is statistically significant with a $P$ value $<0.001$. This means that among girls, the determination of what activity is unpopular depends on their level of physical activity.

Another question examined whether students experienced dread during PE class. Students who listed a particular activity that they dread $(n=246)$ could list 1 to 3 responses. Overall, there were 402 responses listing specific activities that are categorized in Table 4.

The results of relational analysis show significant correlation between dreaded activities and student activity. As shown below in Table 4, ball games are dreaded over three times more by girls, and even more frequently by hypoactive girls. Athletics also tend to evoke a sense of dread among girls, and in hypoactive boys as well. $24.3 \%$ of hypoactive girls mentioned their dread of "Races", while this response was virtually absent in the other student categories.

Graph 3 shows difference in dreaded activities among students by gender and activity. The difference in girls and in hypoactive students is statistically significant with a $P$ value $<0.001$. It can be said that for girls, activities evoking a sense of dread depend on activity and in the category of hypoactive students it depends on gender.

Table 3. Specific activities disliked by individual categories of students

\begin{tabular}{|c|c|c|c|c|}
\hline & Active boys & Hypoactive boys & Active girls & Hypoactive girls \\
\hline Gymnastics & 43 (i.e. $40.6 \%$ ) & 38 (i.e. $67.9 \%$ ) & 77 (i.e. $66.4 \%$ ) & 22 (i.e. $59.5 \%$ ) \\
\hline Ball Games & 34 (i.e. $32.1 \%$ ) & 11 (i.e. $19.6 \%$ ) & 60 (i.e. $51.7 \%$ ) & 14 (i.e. $37.8 \%$ ) \\
\hline Athletics & 17 (i.e. $16.0 \%$ ) & 17 (i.e. $30.4 \%$ ) & 30 (i.e. $25.9 \%$ ) & 27 (i.e. $73.0 \%$ ) \\
\hline Calisthenics & 13 (i.e. $12.3 \%$ ) & 3 (i.e. $5.4 \%$ ) & 10 (i.e. $8.6 \%$ ) & 1 (i.e. $2.7 \%$ ) \\
\hline Strength training & 6 (i.e. $5.7 \%$ ) & 3 (i.e. $5.4 \%$ ) & 10 (i.e. $8.6 \%$ ) & 8 (i.e. $21.6 \%$ ) \\
\hline Other & 11 (i.e. $10.4 \%$ ) & 8 (i.e. $14.3 \%$ ) & 3 (i.e. $2.6 \%$ ) & 2 (i.e. $5.4 \%$ ) \\
\hline Obstacle course & 0 (i.e. $0.0 \%$ ) & 3 (i.e. $5.4 \%$ ) & 3 (i.e. $2.6 \%$ ) & 0 (i.e. $0.0 \%$ ) \\
\hline Tests & 3 (i.e. $2.8 \%$ ) & 4 (i.e. $7.1 \%$ ) & 0 (i.e. $0.0 \%$ ) & 0 (i.e. $0.0 \%$ ) \\
\hline
\end{tabular}


Boys

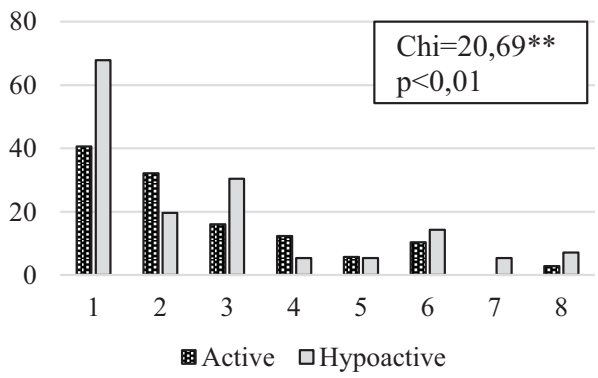

Active

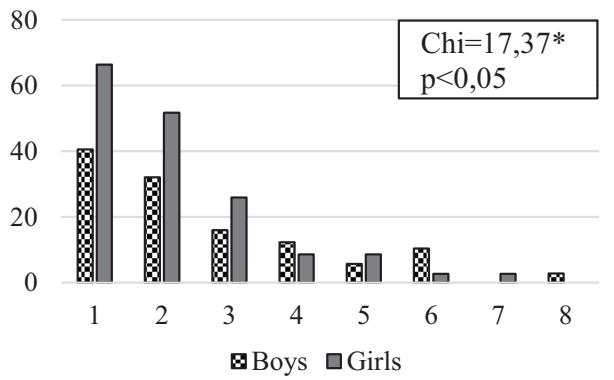

Girls

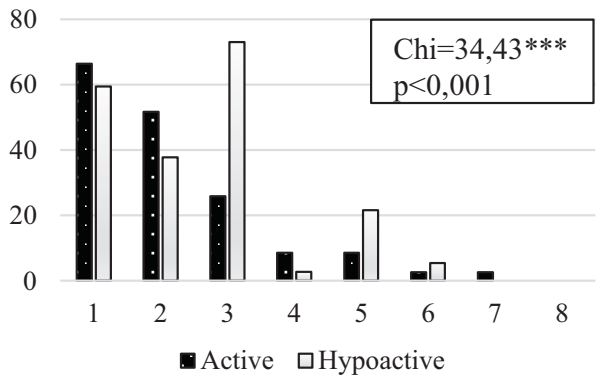

Hypoactive

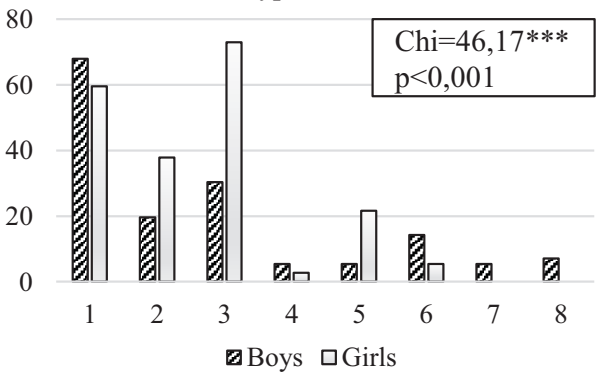

Graph 2. Differences in specific unpopular activities (\% of positive responses)

(1 - gymnastics; 2 - ball games; 3 - athletics; 4 - calisthenics; 5 - strength training; 6 - other;

7 - obstacle course; 8 - tests)

Table 4. Dread of particular activities during PE class

\begin{tabular}{|c|c|c|c|c|}
\hline & Active boys & Hypoactive boys & Active girls & Hypoactive girls \\
\hline Gymnastics & 54 (i.e. $50.9 \%$ ) & 52 (i.e. $92.9 \%$ ) & 86 (i.e. $74.1 \%$ ) & 37 (i.e. $100.0 \%$ ) \\
\hline Ball Games & 10 (i.e. $9.4 \%$ ) & 5 (i.e. $8.9 \%$ ) & 45 (i.e. $38.8 \%$ ) & 15 (i.e. $40.5 \%$ ) \\
\hline Athletics & 4 (i.e. $3.8 \%$ ) & 7 (i.e. $12.5 \%$ ) & 15 (i.e. $12.9 \%$ ) & 6 (i.e. $16.2 \%$ ) \\
\hline Other & 8 (i.e. $7.5 \%$ ) & 3 (i.e. $5.4 \%$ ) & 11 (i.e. 9.5\%) & 3 (i.e. 8.1\%) \\
\hline Injury & 6 (i.e. $5.7 \%$ ) & 3 (i.e. $5.4 \%$ ) & 5 (i.e. $4.3 \%$ ) & 0 (i.e. $0.0 \%$ ) \\
\hline Tests & 5 (i.e. $4.7 \%$ ) & 3 (i.e. $5.4 \%$ ) & 0 (i.e. $0.0 \%$ ) & 0 (i.e. $0.0 \%$ ) \\
\hline Strength training & 2 (i.e. $1.9 \%$ ) & 0 (i.e. $0.0 \%$ ) & 4 (i.e. $3.4 \%$ ) & 2 (i.e. $5.4 \%$ ) \\
\hline Races & 1 (i.e. $0.9 \%$ ) & 1 (i.e. $1.8 \%$ ) & 0 (i.e. $0.0 \%$ ) & 9 (i.e. $24.3 \%$ ) \\
\hline
\end{tabular}

Another question concerned physical activities that the students enjoy during PE class and would like to do more often. Out of the total number of 315 students, 295 submitted responses. The remaining 20 did not give any response. The 295 that responded submitted a total of 526 responses, which are categorized and listed in Table 5.

According to the student responses, all categories would like to see more ball games. This response was more frequent among active students than hypoactive students. The ball games most frequently mentioned by boys were football and volleyball, while volleyball and catch volleyball were most often mentioned by girls. $32.1 \%$ of hypoactive boys mentioned some form 
Boys

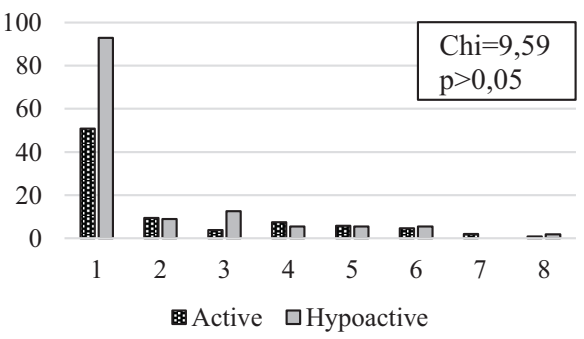

Active

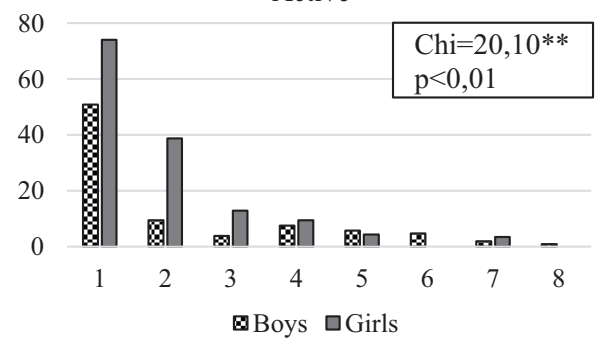

Girls

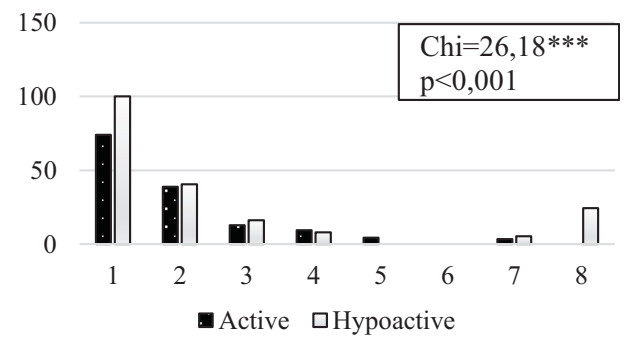

Hypoactive

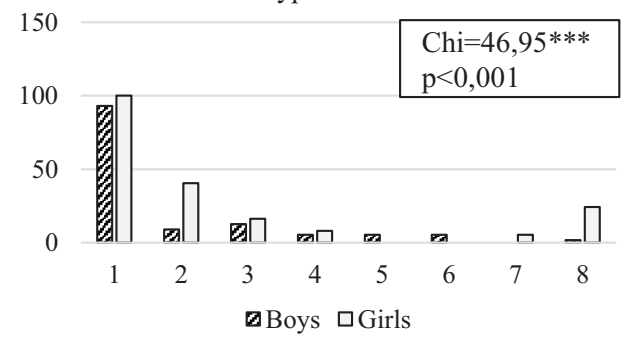

Graph 3. Dreaded activities (\% of positive responses)

(1 - gymnastics; 2 - ball games; 3 - athletics; 4 - other; 5 - injury; 6 - tests; 7 - strength training; 8 - races)

Table 5. PE class wish list

\begin{tabular}{|c|c|c|c|c|}
\hline & Active boys & Hypoactive boys & Active girls & Hypoactive girls \\
\hline Ball Games & 95 (i.e. $89.6 \%$ ) & 36 (i.e. $64.3 \%$ ) & 87 (i.e. $75.0 \%$ ) & 27 (i.e. $73.0 \%$ ) \\
\hline Strength training & 16 (i.e. $15.1 \%$ ) & 18 (i.e. $32.1 \%$ ) & 21 (i.e. $18.1 \%$ ) & 4 (i.e. $10.8 \%$ ) \\
\hline Exercise to music & 1 (i.e. $0.9 \%$ ) & 0 (i.e. $0.0 \%$ ) & 21 (i.e. $18.1 \%$ ) & 18 (i.e. $48.6 \%$ ) \\
\hline Athletics & 16 (i.e. $15.1 \%$ ) & 10 (i.e. $17.9 \%$ ) & 12 (i.e. $10.3 \%$ ) & 0 (i.e. $0.0 \%$ ) \\
\hline Gymnastics & 12 (i.e. $11.3 \%$ ) & 3 (i.e. $5.4 \%$ ) & 20 (i.e. $17.2 \%$ ) & 5 (i.e. $13.5 \%$ ) \\
\hline Swimming & 6 (i.e. $5.7 \%$ ) & 4 (i.e. $7.1 \%$ ) & 8 (i.e. $6.9 \%$ ) & 1 (i.e. $2.7 \%$ ) \\
\hline Outdoor & 6 (i.e. $5.7 \%$ ) & 4 (i.e. $7.1 \%$ ) & 6 (i.e. $5.2 \%$ ) & 4 (i.e. $10.8 \%$ ) \\
\hline Other & 24 (i.e. $22.6 \%$ ) & 8 (i.e. $14.3 \%$ ) & 24 (i.e. $20.7 \%$ ) & 9 (i.e. $24.3 \%$ ) \\
\hline
\end{tabular}

of strength training (core training, work out, weightlifting, CrossFit). Girls more frequently wanted to add exercises with music to PE class (18.1\% active and $48.6 \%$ of hypoactive girls). Specific activities included Zumba, dance and exercise to music.

Graph 4 shows differences in the PE class wish list comparing students by gender and activity. The choice of particular activity for PE class depends on student gender and activity. The greatest difference was seen in the category of hypoactive students. It is statistically significant with a $P$-value $<0.001$. It can be said that the choice of activity by hypoactive students depends on their gender. A significant difference was also shown when comparing the girl groups. Here as well, the choice of activity was statistically dependent on the activity of the girls, with a $P$-value $<0.001$. 


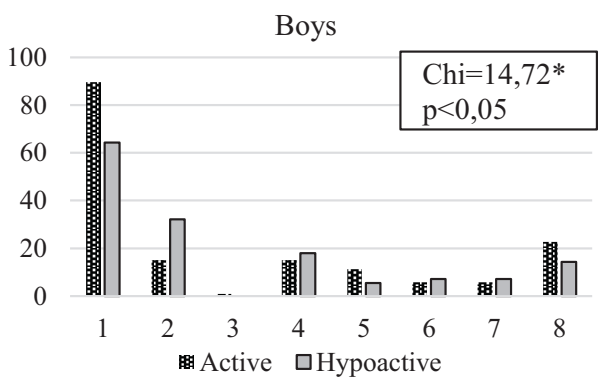

Girls

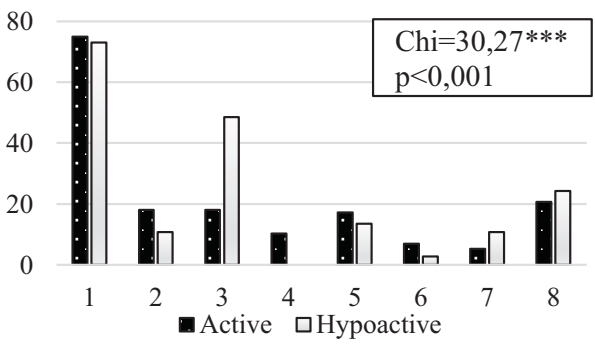

Active

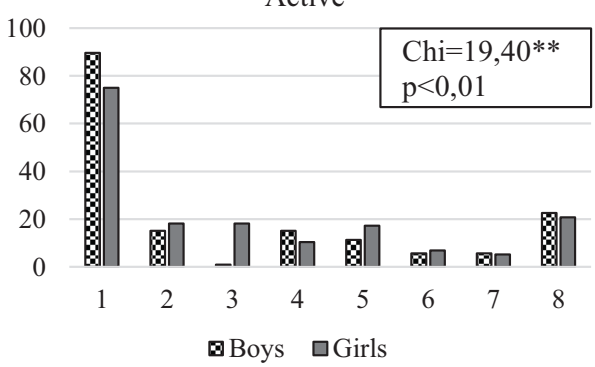

Hypoactive

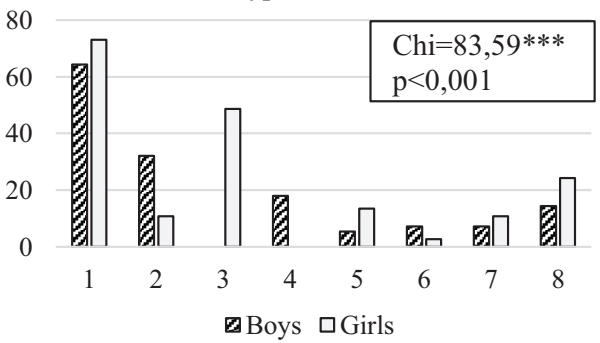

Graph 4. Desire to include specific activities in PE class (\% of positive responses)

(1 - ball games; 2 - strength training; 3 - exercise to music; 4 - athletics; 5 - gymnastics; 6 - swimming; 7 - outdoor; 8 -other)

\section{DISCUSSION}

The health recommendations for minimum daily number of steps are met by $65.4 \%$ of boys and $75.8 \%$ of girls aged $15-16$ years of age studying a secondary vocational schools. Compared with similar research conducted by Sigmund et al. (2017) the number of active girls is nearly the same, but the number of active boys in our study is roughly $10 \%$ higher than in Sigmund's study. The insufficient number of steps was more frequent in the boys' group, for which the recommended minimum is set at 2,000 steps a day more than for girls. That can be a reason for higher occurrence of inactivity in the boys' group. Overall, respondents are rather satisfied with PR curriculum. It has been statistically proven that satisfaction with PE classes depends more on student gender than level of physical activity. Both active and hypoactive boys are statistically more satisfied, while the least satisfied category is hypoactive girls. It can be assumed that inactive girls generally do not like physical activities, so they are dissatisfied with the whole concept of physical education and specific activities do not change ther opinion on PE. Activities that evoke a sense of dread in students are a problem. This is felt at times in PE class by $77.5 \%$ of students. If repeatedly induced, fear and dread can grow into an aversion to particular activities and create a barrier for pursuing them in the future. Dread is more often present among girls than boys and is particularly associated with gymnastics, specifically climbing, exercises on the horizontal bar, as well as vaulting for girls. Dread among girls is also often associated with ball games, especially dodgeball and basketball. Athletics are also dreaded 
by more than $12.5 \%$ of students in all categories except active boys. Running was most often mentioned by girls and the high jump by hypoactive boys. $24.3 \%$ of hypoactive girls are afraid of races, which were mentioned by no more than $1.8 \%$ of students in other categories. According to Bejerot, Edgar, and Humble (2010), for many student races are a possibility to compare themselves. For those who do the worst in the races, similar activities become strongly demotivating and in some cases can evoke emotions of fear, as found in this research. In addition to dread, students disliked a number of activities, led again by gymnastics or some of its disciplines (most frequently mentioned were climbing, exercises on horizontal bars, vaulting), ball games (football for boys, basketball and dodgeball for girls) and athletics, which were mentioned more often by girls (long distance running was most frequently mentioned). Activities that students wanted to do more often included ball games (football for boys, volleyball for girls), strength training (listed by $32 \%$ of hypoactive boys) and exercise to music (listed by $49 \%$ of hypoactive girls). Activities that students would like to do more often are related to their gender. To increase satisfaction with TV lessons, it is therefore essential to divide students into classes according to gender.

\section{CONCLUSION}

The aim of the study was to describe satisfaction with PE class activities while breaking students down by gender and level of physical activity. After summarizing the results, we can say that $41.9 \%$ of high schoolers surveyed exhibited an insufficient amount of movement. The number of steps was found to be insufficient more often in boys, although the recommended daily minimum was 2,000 steps more for boys than girls. It was found that students are rather satisfied with their PE classes, although there are, of course, activities that they dislike or even dread. These were typically gymnastics and its specific disciplines (horizontal bar, climbing, vaulting) and athletics (especially long-distance running), and were most frequently mentioned by hypoactive girls. In future research, we recommend focusing on qualitative research to answer the question: why the activities given above evoke emotions of fear. On the other hand, students have a high appreciation for ball games (football for boys, volleyball for girls), strength training (boys) and exercise to music (hypoactive girls).

Physical education plays an important role in the amount of exercise adolescents get. Therefore, we believe that the proper choice of PE activities can increase the popularity of the class, and thus influence the exercise habits of adolescents, including those who are found to have insufficient physical activity. Analysis of the remaining part of the questionnaire, which describes other opinions of secondary school students regarding school physical education, is part of the dissertation work of Katerina Kralova.

Conflicts of interest: The authors have no conflicts of interest to declare.

\section{REFERENCES}

Alkhatib, A. (2016). Sedentary lifestyle: Predictive factors, health risks and physiological implications. New York: Nova Publishers. ISBN 9781634846738. 
Antala, B., Šimonek, J., Čillík, I., Labudová, J., Medeková, H., Bebčáková, V., et al. (2012). Telesná a športová výchova $v$ názoroch žiakov základných a stredných škôl. Bratislava: END. ISBN 9788089324095.

Arnett, J. J., \& Jensen, L. (2019). Human development: A cultural approach (3rd ed., pp. 328-433). New York, NY: Pearson. ISBN 978-0-13-464134-8.

Bejerot, S., Edgar, J., \& Humble, M. (2010). Poor performance in physical education - A risk factor for bully victimization. A case-control study. Acta Pediatrica, 100(3), 413-419.

Bélanger, M., Sabiston, C. M., Barnett, T. A., O’loughlin, E., Ward, S., Contreras, G., et al. (2015). Number of years of participation in some, but not all, types of physical activity during adolescence predicts level of physical activity in adulthood: Results from a 13-year study. International Journal of Behavioral Nutrition and Physical Activity, 12(76), 1-8.

Brettschneider, W. D., \& Naul, R. (2007). Obesity in Europe: Young people's physical activity and sedentary lifestyles (4th ed.). Oxford: Peter Lang. ISBN 978-363-1564-691.

Chang, M. O. (2015). The study of leisure time use of older adults: To seek the directions of lifelong education in later life for Homo hundred. Journal of Fisheries and Marine Sciences Education, 27(1), 203-217.

Church, T. S., Thomas D. M., Tudor-Locke C., Katzmarzyk P. T., Earnest C. P., Rodarte R. Q., et al. (2011). Trends over 5 decades in US. Occupation-related physical activity and their associations with obesity. Plos One, 6(5).

Coll, C. D. V. N., Knuth, A. G., Bastos, J. P., Hallal, P. C., \& Bertoldi, A. D. (2014). Time trends of physical activity among Brazilian adolescents over a 7-year period. Journal of Adolescent Health, 54(2), 209-213. ISSN 1879-1972.

Cruiz, J. (2017). Obesity weight loss: Sedentary lifestyle [online]. Budapest: PublishDrive, [cit. 2020-03-08]. ISBN 9781521012949. Retrieved from: https://www.kobo.com/my/en/ebook/obesity-weight-loss.

Diehl, K., \& Hilger, J. (2015). Nutrition and physical activity during the transition from adolescence to adulthood. International Journal of Adolescent Medicine and Health, 27(1), 101-104. ISSN 0334-0139.

Dishman, R. K., Heath, G., \& Lee, I. M. (2013). Physical activity epidemiology (2nd ed.). Champaign, IL: Human Kinetics. ISBN 978-073-6082-860.

Gába, A., Rubín, L., Badura, P., \& Roubalová, E. (2018). Results from the Czech Republic's 2018 report card on physical activity for children and youth. Journal of Physical Activity and Health, 15(2), 338-340.

Harris, J., \& Cale, L. (2018). Promoting active lifestyles in schools. Champaign, IL: Human Kinetics. ISBN 978149253381.

James, M., Todd, C., Scott, S., Stratton, G., McCoubrey, S., Christian, D., et al. (2018). Teenage recommendations to improve physical activity for their age group: A qualitative study. BMC Public Health, 18, 372.

Jansa, P. (2017). Komparace postojů a názorů adolescentů ve věku 15-18 let ke sportu a pohybovým aktivitám. Studia Sportiva, 11(1), 90-99.

Logstrup, S. (2001). Children and young people: The importance of physical activity. Brussel: European Heart Health Initiative.

Meyer, A. L., \& Gullotta, P. (2012). Physical activity across the lifespan: Prevention and treatment for health and well-being. New York: Springer. Issues in children's and families' lives. ISBN 978-14614-3605-8.

Powell, D. (2020). Schools, corporations, and the war on childhood obesity: How corporate philanthropy shapes public health and education. New York: Cenveo Publishers Services. ISBN 978-0-8153-5514-4. 
Sigmundová, D., Sigmund, E., Bucksch, J., Bad’ura, P., Kalman, M., \& Hamř́ík, Z. (2017). Trends in screen time behaviours in Czech schoolchildren between 2002 and 2014: HBSC study. Central European Journal of Public Health, 25(88), 15-20.

Smith, P. K. (2016). Adolescence: A very short introduction. New York, NY: Oxford University Press. Very short introductions. ISBN 978-0-19-966556-3.

Telama, R., Yang, X., Leskinen, E., Kankaanpaa, A., Hirvensalo, M., Tammelin, T., et al. (2014). Tracking of physical activity from early childhood through youth into adulthood. Medicine and Science in Sports and Exercise, 46(5).

Open Access. This is an open-access article distributed under the terms of the Creative Commons Attribution-NonCommercial 4.0 International License (https://creativecommons.org/licenses/by-nc/4.0/), which permits unrestricted use, distribution, and reproduction in any medium for non-commercial purposes, provided the original author and source are credited, a link to the CC License is provided, and changes - if any - are indicated. 